Article

\title{
Digital Transformation Reduces Costs of the Paints and Coatings Development Process
}

\author{
Tomaž Kern *, Eva Krhač Andrašec, Benjamin Urh and Marjan Senegačnik \\ Laboratory of Enterprise Engineering, Faculty of Organizational Sciences, University of Maribor, \\ Kidričeva cesta 55a, 4000 Kranj, Slovenia; eva.krhac1@um.si (E.K.A.); benjamin.urh@um.si (B.U.); \\ marjan.senegacnik@um.si (M.S.) \\ * Correspondence: tomaz.kern@um.si; Tel.: +386-(0)4-23-74-279
}

Received: 24 June 2020; Accepted: 20 July 2020; Published: 21 July 2020

\begin{abstract}
An essential characteristic of the new product development process is to develop a new marketable product in the shortest possible time with the lowest reasonable costs. Therefore, the key factor of the process is efficiency. The paints and coatings industry development process contain numerous laboratory tests to determine the appropriateness of new formulation. It is proven that digital transformation can reduce the number of laboratory tests and consequently shorten the throughput time of the development process. This raised the question of whether the faster development process also reduces the process' cost, or they even increase due to information and communication technology implementation. Therefore, the research's purpose was to determine whether reducing the number of laboratory tests, based on the implementation of information and communication technology (ICT), affects reducing costs in the paints and coatings development process. The conventional process and the redesigned process of paints and coatings development were used as the basis of the research. The comparative analysis of the costs incurred during the development process was made. The analysis compares the types and amount of incurred costs. The article proves that digital transformation has a significant impact on up to $48 \%$ on reducing costs of the paints and coatings development process.
\end{abstract}

Keywords: coatings industry; digital transformation; development process; process redesign; technical enabler; implementation cost; rentability threshold

\section{Introduction}

Manufacturers in the paints and coatings industry are facing increasing customers' demands for paints and coatings that ensure adequate protection of the substrate, meet the relevant aesthetic criteria, and consider environmental protection and health safety requirements [1,2]. Time "from demand to product" has to be as short as possible $[3,4]$. At the same time, manufacturers have to have costs of a product in mind.

Optimizing these factors when developing a product is an extremely demanding task. Moreover, manufacturers are faced with heavy competition. For example, in the EU-28 in 2016 were 3865 companies involved in the manufacture of paints, lacquers, and related coatings, printer inks, and body fillers [5].

According to Partidário and Verdragt [6], the paint (coating) chain consists of the following phases: 1. production and supply of ingredients, 2. paint (coating) production, 3 . research and development (R\&D), 4. coating applications, 5 . use of a product protected by coating, and 6 . waste management (end of life product disposal or recycling). However, as the entire lifecycle of a product has to be taken into account when examining the economic aspects, any examination of economic impact cannot ignore the research and development phase (R\&D). 
As the number of requirements regarding the quality and aesthetic criteria of coatings is increasing all the time, the development process is becoming more and more complex [7-10]. Coating formulations include various ingredients, such as resins, additives, pigments, fillers, catalysts, solvents, co-solvents, water, etc. Exploring all possible combinations in search of the best formulation is impossible, especially on the benchtop, which allows for a limited number of options to be explored. To better visualize what that means, the senior manager of R\&D Additives (Evonik Resource Efficiency GmbH) presents an example: "If ten resins, ten additives, ten pigments, and ten catalysts were to be considered for a formulation, 10,000 combinations are possible without considering different quantities for each". It is necessary to explore a large number of possible combinations to find the optimal formulation, which is possible only with high-throughput technology [11].

Therefore, the development includes a considerable amount of laboratory work, from synthesis and mixing of ingredients to the testing of the effectiveness and durability of coatings [12]. With coatings having to ensure adequate protection for as long as possible, laboratory testing often takes place under strict conditions that require well-trained professionals and expensive laboratory equipment. It is, therefore, clear that laboratory activities cause high costs.

In practice, it is often the case that a coating that has successfully passed a long series of laboratory tests does not meet environmental standards, health safety requirements, or economic constraints. Therefore, it would make sense to check in advance whether the proposed formulation meets all those requirements. This would avoid time-consuming and costly laboratory procedures for unmarketable products.

These hypotheses have been posed when the coatings development process was studied. The research's purpose was to investigate whether the process can be rationally improved (according to the above requirements) using cloud-based information technology and a big data approach. In order to conduct research, a sample of several small and medium-sized companies involved in the production of coatings was selected. All these enterprises perform the development process mostly in a conventional manner without information technology, which would enable digital transformation.

In the article "Digitalizing the Paints and Coatings Development Process" [3] has been proved that the inclusion of the appropriate information and communication technology (ICT) support in the new product development process helped to reduce the entire development process throughput time significantly. However, the purpose of the present research was to determine whether reducing the number of laboratory tests, based on the implementation of information and communication technology (ICT), affects reducing costs in the paints and coatings development process. The primary aim of the research was to prove that reducing the number of laboratory tests has the effect of reducing costs in the paints and coatings development process. For research integrity, it is essential to take into account the costs incurred with the implementation of digital technology, which was our secondary aim. As a tertiary aim of the research, we designed a calculator to calculate the actual rentability threshold of digital process transformation in a specific case.

The present paper describes an example of process redesign, which will contribute to the lower costs of the developing process. In the following section (Section 2), the research procedure is described. Then, the results of the research are presented (Section 3). The article is concluded with a discussion and a conclusion of the research (Section 4).

\section{Materials and Methods}

For the research, it was necessary to prepare two models of the paints and coatings development process execution:

- The conventional practice of process execution - presented with the As-Is model,

- Process execution after the digital transformation—-presented with the To-Be model. 
The ARIS tool was used to prepare these models. The process modeling methodology is described in detail in Kern et al. [3]. In this article, as a continuation of previous research [3], we focused on the cost aspect of improving business processes as a result of digital technology implementation.

For a cost analysis of digital process transformation, it is necessary to monitor the costs of executing an individual activity of the development process (activity-based costing method) and also the costs of implementing digital technology.

The activity-based costing ( $A B C$ ) method follows the cost via activities performed on the cost objectives (production or service activities). Using ABC can lead to classifying activities as value-added and non-value-added, and allow for the elimination of the non-value-added activities. Therefore, $\mathrm{ABC}$ is an accurate cost estimation and calculation method $[13,14]$.

Furthermore, a theoretical overview of the information system's implementation costs was prepared based on different recommendations of various authors, which can be found in the literature:

- Licensing fees ("on-premises vs. cloud-hosted"), implementation costs, training costs, integration costs, development costs, support costs, and maintenance and upgrade costs [15];

- Labor costs, training costs, testing costs, re-engineered processes costs, change management costs, customization and integration costs, customer dissatisfaction costs, and ongoing support and maintenance costs [16].

Similarly, Barreau [17] argues that the costs associated with the purchase, implementation, and operation of information systems exceed the cost of hardware and software. Based on a work-centered analysis, Alter [18] notes the following categories of omissions in the preparation of the invoice for implementation:

- The salary of staff and management involved in the implementation and analysis,

- Labor costs that have been interrupted or delayed due to system implementation,

- The cost of the work environment's adjustment—-technical and ergonomic [19] adjustments,

- Cost and time spent on employee training.

Barreau [17] adds two categories where costs may be inadvertently overlooked: adjustment of existing systems or processes and the consequences of budget overruns. The author also mentions the costs that are usually hidden during operation and maintenance. Those costs are undervalued or even not expected. Examples of those costs are the impact on organizational work (process redesign's cost or process adjustment's cost) and technical support (support staff).

The division of the information system's implementation costs was analyzed in detail by Irani et al. [20]. For the present research, we have adjusted this division of costs:

Costs for a provider: development, security, hardware, custom software, system software, cabling/building, support, modification, cost of ownership, system support, infrastructure, and training (preparation and execution) costs.

Costs for user:

- Licensing fees, which include: package software, licenses and upgrades costs, and operations costs;

- Implementation costs, which include: implementation, installation, configuration, management effort and dedication, employee motivation, employee time and strains on resources costs, and data communication;

- Maintenance costs, which include: maintenance of the system and maintenance of data;

- Training costs, which include: training (study time and course participation time) costs;

- Change management costs, such as project management, management time, communication, management/staff resources, overheads, software disposal, hardware disposal, business process re-engineering (BPR), organizational restructuring, staff-related costs (changes in salaries), and commissioning costs;

- Opportunity costs, which include: opportunity costs and risks, implementation risks (covert resistance), productivity loss, and personnel issues costs. 
The costs of implementing information systems also depend on their specifications, so we provide some essential information about the technical enabler for the digital transformation [21-23]. A technical enabler for the proposed improvement of the development process has been developed and is used as an information tool of the fourth generation [24]. The tool is the only all-in-one tool that enables online, real-time searching for ingredients, virtual formulation of paints and coatings, and the creation of digital technical and safety data sheets. The formulator uses ingredients data from the structured database, which is available in the digital form in a cloud. The re-engineering point is that the formulator has instant and free access to a large number of ingredients and is guided by the platform to select only those that are functionally relevant, safe, environmentally acceptable, and affordable, even before the individual formulation is laboratory-tested [3]. Therefore, we can extract three main properties of the technical enabler from the perspective of the current research:

- The technical enabler is cloud-based information technology,

- The provider of technical enabler covers system maintenance costs,

- The provider performs web-based training.

We set up a calculation on how to calculate the cost of the tool's implementation and the rentability threshold. The calculation is prepared based on a review of process redesign literature, savings based on process redesign (enabling by ICT), possible implementation costs, and tool specifications. The ICT solution provider's costs were not taken into account in the calculation, as the research was focused on the rentability threshold of digital process transformation from the user's point of view.

The equation for calculation of rentability threshold is:

$$
X \cdot \Delta C_{p d} \geq C_{D T}
$$

The equation's variables:

$X$-the number of newly developed products when digital transformation rentability threshold is reached,

$\Delta C_{p d}$-the difference between the average cost of executing the process in a conventional manner and the average cost of executing the process after digital transformation,

$C_{D T}$ - costs of digital transformation.

We can substitute $\Delta \mathrm{C}_{\mathrm{pd}}$ with variables obtained by the process analysis.

$$
\Delta C_{p d}=C_{p d 1}-C_{p d 2}
$$

$C_{p d 1}$-the average cost of new product development in a conventional manner (before digital transformation),

$C_{p d 2}$ - the average cost of new product development after digital transformation.

Therefore, the final equation is:

$$
X \geq \frac{C_{D T}}{\left(C_{p d 1}-C_{p d 2}\right)}
$$

\subsection{Product Development's Costs $\left(\Delta C_{p d}\right)$}

The difference between the average cost of executing the process in a conventional manner and the average cost of executing the process after the digital transformation is present by $\Delta$ product development costs.

In the calculation, the following savings were taken into account:

- A smaller number of laboratory tests,

- Lower material consumption, 
- Less labor (due to shorter activities times).

The smaller number of laboratory tests is the result of a changed sequence of activities, which was made possible by the digital transformation of the process (checking the functionality relevance, safety, environmental acceptance, and affordability before the formulation is laboratory-tested). The difference in costs due to the smaller number of laboratory tests can be seen from the comparison of As-Is and To-Be process models and the cost of their execution.

Additionally, the amount of material consumed in the laboratory tests decreases due to the smaller number of tests. In this case, the reduction of material costs is defined by the following formula:

$$
P_{m}=\sum_{i=1}^{n} m_{i} \cdot p_{i}
$$

The equation's variables:

$P_{m}$-material costs,

$n$-the number of ingredients in the formulation,

$m_{i}$ - the mass of each ingredient in the formulation (rounded up to the packaging unit),

$p_{i}$-the price of each ingredient's packaging unit.

Additionally, due to shorter activities times, the redesigned process results in lower labor costs. This variable takes into account already prepared calculations. The following data were taken into account in the calculations: the average labor cost for the employer (for chemistry) in 2019 and the factor of the minimum net salary for each level of education in chemistry $[25,26]$.

The following savings (opportunity savings) could not be taken into account in the calculation, as data was not currently available:

- Less workload due to shorter development time,

- Faster ingredient purchase,

- The lower purchase price,

- Cheaper handover of ingredients.

However, opportunity savings could be measured after the actual implementation of the tool and after a specific time. So, we will be able to take them into account in future research in the form of a longitudinal study.

\subsection{Costs of Digital Transformation $\left(C_{D T}\right)$}

According to the presented recommendations of various authors, the information system's implementation costs were structured to licensing fees, implementation costs, maintenance costs, training costs, change management costs, and opportunity costs.

$$
C_{D T}=C_{l}+C_{i}+C_{m}+C_{t}+C_{c}+C_{o}
$$

The equation's variables:

$C_{D T}$ - costs of digital transformation,

$C_{l}$-licensing costs,

$C_{i}$-implementation costs,

$C_{m}$-maintenance costs,

$C_{t}$-training costs,

$\mathrm{C}_{c}$ - change management costs,

$\mathrm{C}_{0}$-opportunity costs (due to the elimination of existing tools). 
Licensing costs $\left(C_{l}\right)$ are divided into several options, among which, depending on the specifications of each provider's option, the customer decides which is the most suitable for the company. In addition to the basic licensing options, the customer can choose a few additional optional functionalities of the information system.

Implementation costs $\left(C_{i}\right)$, in this case, include the costs of data adaptation and the costs of interface development between the chosen tool that enables digital transformation and the enterprise information system. In the case of the chosen tool, six different adaptation cost scenarios are possible:

- Manual data input (on new ingredients from safety data sheets) - by the provider,

- Manual data input (on new ingredients from safety data sheets) — by the user,

- Manual formulation input (by the provider),

- Manual formulation input (by the user),

- Automatic capture by the parsing of the safety data sheets (.pdf format) and manual correction of the data,

- Automatic data transfer from the ERP system.

To calculate adaptation costs, we executed an experiment in which manual input scenarios were captured. The experiment consisted of two parts: data input of new ingredients and formulation input. In both parts, we measured the input time by an expert (an employee of a technical enabler's provider, which masters the technical enabler) and by new users (an employee of a user, which is an expert in the development of paints and coatings but had no previous experience with the technical enabler). The last two options, which include the development of an interface for transfer data were not analyzed in detail in the present research, because the costs can not be predicted since they vary from company to company and the business systems they have used.

Maintenance costs $\left(C_{m}\right)$ can be roughly divided into the cost of maintaining system and data maintenance costs. There are no system maintenance costs for users in case of cloud-based solutions because the license fee covers costs. Additional maintenance costs include only the maintenance of data that is updated depending on changes during use.

Training costs $\left(C_{t}\right)$ are dependent on the form of training. In the present case, the training is provided in the digital form. The cost of digitized training consists of the following factors [27]:

- The preparative tasks of the trainer,

- The working time required to engage the trainer during the training,

- The working time needed for the active participation of the participants during the training,

- An e-learning platform.

The advantage of digital training tools is that they reduce the overall cost of training since there is no trainer travel costs and classroom rental costs in terms of fixed costs. There is also no travel cost for training participants, potential temp arrangements per participant per hour, material, and refreshments costs per participant, and other additional costs per participant [27].

In the previously mentioned experiment (in implementation costs $\left(C_{i}\right)$ ), we also included the calculation of training costs, as new users completed training before measuring the times of data input (of new ingredients) and formulation input.

According to Saunders, Ganly, and Torii [28], change management costs $\left(C_{c}\right)$ can be estimated at $15 \%$ of costs of digital transformation $\left(C_{D T}\right)$.

Opportunity costs $\left(C_{o}\right)$ are not considered separately in the present case study, as they were already taken into account in the transformation of the conventional manner of execution of the process into the execution of the process after the digital transformation. 


\section{Results}

\subsection{Costs Analysis of the Existing Paints and Coatings Development Process}

During the process analysis of paints and coatings (product) development in different companies, we found that they could be roughly divided into two groups:

- The conventional process of new product development without ICT support,

- New product development process with ICT support and the use of a local database.

Scheme 1 shows the sequence of key activities execution in the conventional process of product development.

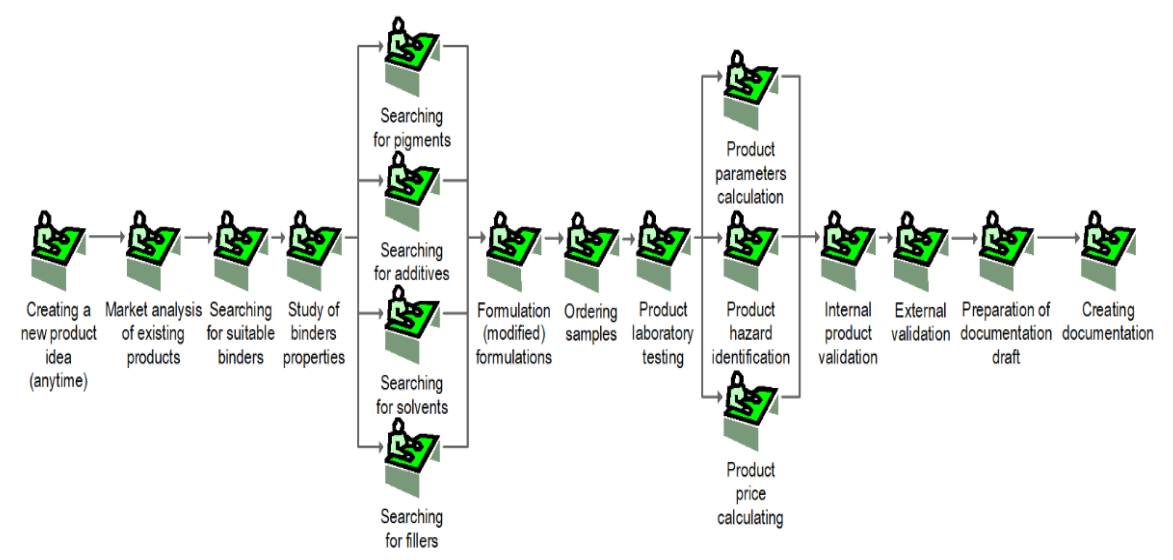

Scheme 1. The model overview of the conventional new product development process.

The results of the process activities analysis are shown in Table 1 below: data on their execution probability, the amount of work required for the successful execution of the individual activity, the cost of labor per hour, and the cost of successful activity's execution. The cost of each activity's execution and the overall process was calculated using the following formulas.

The equation for activity cost calculation is:

$$
c_{i}=t_{i} \cdot p_{i}
$$

The equation for the total product development cost is:

$$
C=\sum_{i=1}^{n} c_{i}=\sum_{i=1}^{n} t_{i} \cdot p_{i}
$$

The equation's variables with measurement unit:

$c_{i}$ - the cost of a particular activity $(€)$,

$t_{i}$-time of particular activity $(h)$,

$p_{i}$-the price of work per hour for a particular activity $(€ / h)$,

$C$ - the total cost of product development $(€)$.

Based on this, the average employer's cost of one hour of the employee's work who performs or participates in the execution of the activity, taking into account the different levels of the employee's education. Since the level of education of employees in a specific workplace varies between companies, in the present case, we took into account the average hourly rate between an engineer and an MSc for the formulator workplace. For the workplace of development manager, we took into account the average hourly rate between the MSc and the Ph.D. 
Table 1. Key activities of the conventional new product development process.

\begin{tabular}{|c|c|c|c|c|c|}
\hline \multicolumn{6}{|c|}{ The Conventional New Product Development Process } \\
\hline 10 & Creating a new product idea & 0.06 & 10.31 & 21.95 & 226.36 \\
\hline 20 & Market analysis of existing products & 1.00 & 165.00 & 25.35 & 4181.93 \\
\hline 50 & Searching for pigments & \multirow{4}{*}{0.19} & 10.63 & 25.35 & 269.29 \\
\hline 60 & Searching for additives & & 13.13 & 25.35 & 332.65 \\
\hline 70 & Searching for solvents & & 3.33 & 25.35 & 84.48 \\
\hline 80 & Searching for fillers & & 3.33 & 25.35 & 84.48 \\
\hline 120 & Product parameters measurement & \multirow{3}{*}{0.40} & 5.44 & 25.35 & 137.99 \\
\hline 130 & Product hazard identification & & 39.44 & 25.35 & 999.72 \\
\hline 140 & Product price calculating & & 16.11 & 25.35 & 408.34 \\
\hline 150 & Internal validation & 0.50 & 600.89 & 21.95 & $13,189.51$ \\
\hline 160 & External validation & 0.75 & 23.47 & 21.95 & 515.09 \\
\hline 170 & Preparation of documentation draft & 1.00 & 5.37 & 21.95 & 117.80 \\
\hline \multirow[t]{2}{*}{180} & Creating documentation & 1.00 & 18.70 & 21.95 & 410.47 \\
\hline & Total product development costs: & & 2245.52 & & $50,326.83$ \\
\hline
\end{tabular}

${ }^{1}$ The probability of executing an individual activity according to the decisions during the process. With the exclusion of activity " 10 ", there exists a probability that the activity is included in the process. Probabilities for activities that are running parallel (simultaneously) can be found in merged fields. ${ }^{2}$ The average amount of work that employees in the company must perform in an individual activity at the time of one completed process of product development. The scope of work for the successful completion of an individual activity includes preparation-finishing times and processing times. However, the work of external institutions is not included (external validation). ${ }^{3}$ The average labor cost for the employer (for chemistry) in 2019 is $16.75 € / \mathrm{h}$ and the factor of the minimum net salary for each level of education in chemistry is: an engineer-1.203, MSc - 1.481, and Ph.D.-1.716 [25,26]. Based on these calculations, we obtained the following three labor costs for the employer according to the employee's educational level:

- Labor costs for the employer 2019, engineer, chemistry $=16.75 € / \mathrm{h} \times 1.203=20.15 € / \mathrm{h}$

- $\quad$ Labor costs for the employer 2019, MSc, chemistry $=16.75 € / \mathrm{h} \times 1.481=23.75 € / \mathrm{h}$

- $\quad$ Labor costs for the employer 2019, Ph.D, chemistry $=16.75 € / \mathrm{h} \times 1.716=28.74 € / \mathrm{h}$.

\subsection{The Paints and Coatings Development Process Redesign}

In the conventional manner of process execution, it is not uncommon that a product that has passed the exacting testing phase and shown itself to be technologically suitable (effective, durable, etc.) is shown not to meet environmental and health standards. The cause is an unsuitable composition-something that could have been established at the initial stage. For such formulations, the laboratory testing phase could have been avoided for saving costs, time, materials, and energy.

The solution that avoids this problem and shortens the development process by using modern ICT is already known and described in detail in Kern et al. [3]. In this article, we were focused on how the proposed changes affect the cost aspect of the process, and for that purpose, an appropriate model of the redesigned process was developed (shown in Scheme 2).

\subsection{Results of the Redesigned Process Costs Analysis}

The possibilities offered by the inclusion of process support with modern ICT and the use of a cloud-based database were taken into account, which allowed the inverted sequence of key activities execution in the process (Table 2). This significantly influenced the number of laboratory tests and, consequently, on costs. 


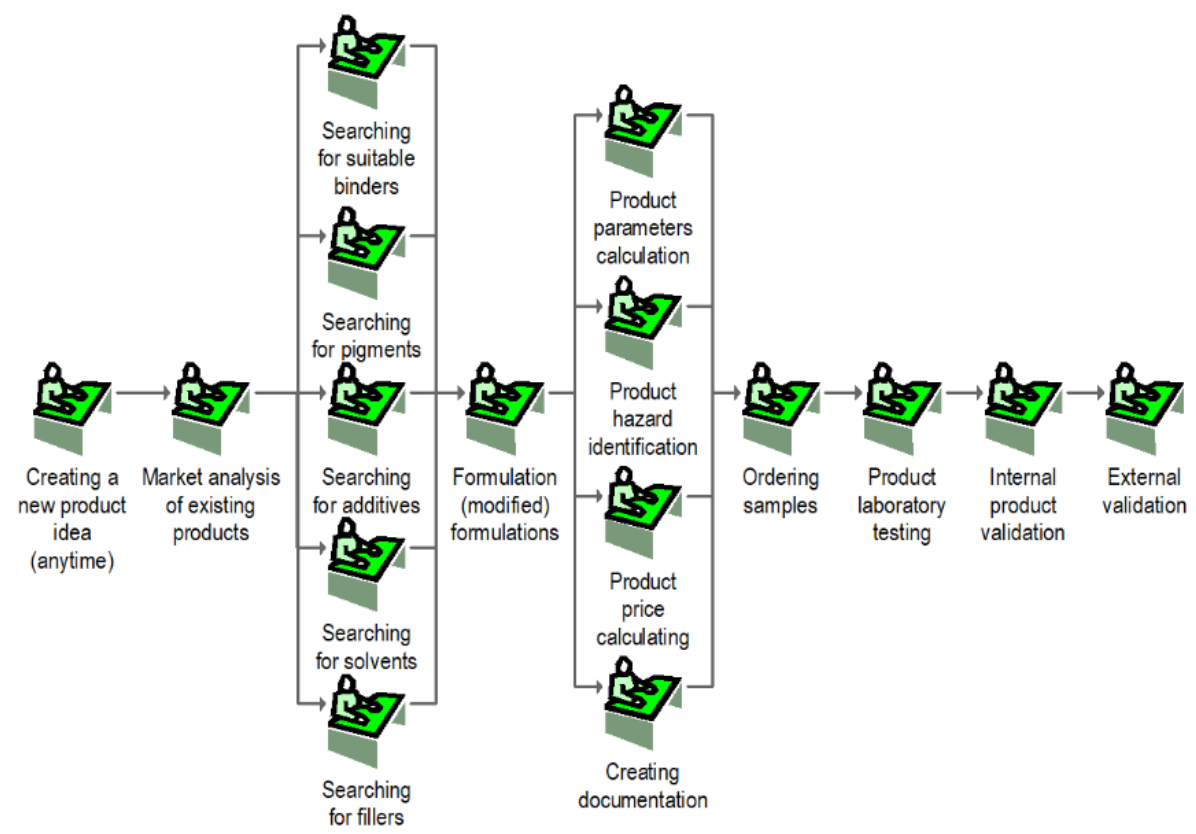

Scheme 2. The model overview of the modified (redesigned) new product development process after digital transformation.

Table 2. Key activities of the new product development process after the digital transformation.

\begin{tabular}{|c|c|c|c|c|c|}
\hline \multicolumn{6}{|c|}{ New Product Development Process after Digital Transformation } \\
\hline \#\# & Process Activities & Probability $^{1}$ & $\begin{array}{l}\text { Work for One } \\
\text { Successful } \\
\text { Product }^{2} \text { (h) }\end{array}$ & $\begin{array}{l}\text { The Cost of } \\
\text { One Work's } \\
\text { Hour }^{3}(\epsilon)\end{array}$ & $\begin{array}{l}\text { The Cost of } \\
\text { Activity } \\
\text { Execution (€) }\end{array}$ \\
\hline 10 & Creating a new product idea & 0.06 & 4.64 & 21.95 & 101.86 \\
\hline 20 & Market analysis of existing products & 0.92 & 82.50 & 25.35 & 2090.96 \\
\hline 30 & Searching for suitable binders & \multirow{5}{*}{0.19} & 0.53 & 25.35 & 13.46 \\
\hline 40 & Searching for pigments & & 0.53 & 25.35 & 13.46 \\
\hline 50 & Searching for additives & & 0.66 & 25.35 & 16.63 \\
\hline 60 & Searching for solvents & & 0.17 & 25.35 & 4.22 \\
\hline 70 & Searching for fillers & & 0.17 & 25.35 & 4.22 \\
\hline 80 & Formulation (modified) formulations & 1.00 & 1.44 & 25.35 & 36.61 \\
\hline 90 & Product parameters calculation & \multirow{4}{*}{0.80} & 0.00 & 25.35 & 0.00 \\
\hline 100 & Product hazard identification & & 0.00 & 25.35 & 0.00 \\
\hline 110 & Product price calculating & & 3.22 & 25.35 & 81.67 \\
\hline 120 & Creating documentation & & 62.33 & 21.95 & 1368.22 \\
\hline 130 & Ordering samples & 1.00 & 2.58 & 21.95 & 56.58 \\
\hline 140 & Product laboratory testing & 0.50 & 374.67 & 21.95 & 8223.93 \\
\hline 150 & Internal validation & 0.50 & 600.89 & 21.95 & $13,189.51$ \\
\hline \multirow[t]{2}{*}{160} & External validation & 0.75 & 23.47 & 21.95 & 515.09 \\
\hline & Total product development cos & & 1157.79 & & $25,716.45$ \\
\hline
\end{tabular}

${ }^{1-3}$ The same notes as for Table 1.

Based on the comparison of the results of the existing process analysis (total costs were $50,326.83 €$ -Table 1) and the results of the proposed redesigned process (total costs were 25,716.45€-Table 2), we could see that the digital process transformation reduced the direct costs of the development process by up to $48 \%$. 


\subsection{The Costs of Digital Transformation (Case Results)}

In the digital transformation execution of the new product development process, the ICT solution was used as an enabler of the redesign. In the following, costs were calculated assuming the use of a technical enabler (which in the present case is Allchemist) [24] and the division described in the subsection "Costs of digital transformation $\left(\mathrm{C}_{\mathrm{DT}}\right)^{\text {". }}$

\subsubsection{Licensing Costs}

The cost depends on the type of selected license. It varies depending on the number of users, the number of products marketed by the company, and the additional functionalities of the chosen tool. It is possible to choose between free of charge usage $(1$ user) and payable options ( $150 € /$ month for five users and $2500 € /$ month for ten users), and the possibility of payment for additional users. Rental fee payment for additional functionalities, such as regulatory dashboard and safety data sheet (SDS) creation, is also regulated according to the scope of additional functionalities [29].

In further calculations, we took into account the licensing costs in the case of a company that needs the full functionality according to the process requirements and:

- Five employees participated in the development process,

- Prepared and managed 500 SDS per month,

- Used 200 hazardous ingredients,

- Had up to 300 active ingredients in the database,

- Had up to 100 active formulations (products) in the database.

$$
C_{l}=C_{\mathrm{cl}}+C_{\mathrm{cSDS}}+C_{\mathrm{cRD}}=150 € / \text { month }+299 € / \text { month }+65 € / \text { month }=514 € / \text { month }
$$

The equation's variables:

$C_{l}$-licensing costs,

$\mathrm{C}_{\mathrm{cl}}$ - the costs of the selected license ( $€ /$ month),

$\mathrm{C}_{\mathrm{cSDS}}$ - the costs of the selected scope of SDS creation ( $€ /$ month),

$\mathrm{C}_{\mathrm{CRD}}$-the costs of the selected scope of the regulatory dashboard $(€ /$ month).

\subsubsection{Implementation Costs}

The minimum system requirements for the user are a device with an Internet browser and an Internet connection. In the research, we assumed that an individual user already fulfills the mentioned requirements.

For the present research, a smaller company was selected, which usually does not decide to integrate the tool with ERP but enter ingredients and formulation data manually. Therefore, we executed an experiment to estimate the time required for the database adaptation.

We invited four new, inexperienced users to experiment. We measured the input times of each user for ten different ingredients and ten different formulations. Based on the measured times, we calculated the average time required for the input of individual ingredient and formulation into the database. The average time for ingredients input was $32.03 \mathrm{~min}$ ( or $0.534 \mathrm{~h}$ ), with a standard deviation of $7.14 \mathrm{~min}$. The average time for formulation input was $11.56 \mathrm{~min}$ (or $0.193 \mathrm{~h}$ ), with a standard deviation of $5.49 \mathrm{~min}$. We also measured times for experienced users. An experienced user entered the ingredient with an average of $17.99 \mathrm{~min}$ with a standard deviation of $1.84 \mathrm{~min}$. An experienced user's formulation input was, on average, $4.41 \mathrm{~min}$ with a standard deviation of $0.62 \mathrm{~min}$. The positive learning curve can be confirmed from the present data. For the experiment, we used only inexperienced users' times.

Based on these data and based on the assumption that data on ingredients and formulations in the company were entered by a development employee with an average hourly rate of $24.21 € / h[25,26]$, we calculated the costs of database adaptation. 
The cost of adaptation includes:

- Ingredients input,

300 ingredients $\times 0.534 \mathrm{~h} \times 24.21 € / \mathrm{h}=3877 €$

- Formulation input,

$$
100 \text { formulations } \times 0.193 \mathrm{~h} \times 24.21 € / \mathrm{h}=466 €
$$

The cost of implementing the chosen tool in a small company that has up to five employees in the development process can be estimated at $€ 4350$.

\subsubsection{Maintenance Costs}

Formulators included in the research estimated that $40 \%$ of the ingredients in the database needed to be reviewed and corrected annually. Reviewing and correcting data on an individual ingredient in practice means re-entering the ingredient into the database. Maintenance costs can be estimated based on ingredients input costs as well as:

$$
3877 € \times 40 \% / \text { year }=1551 € / \text { year }
$$

The maintenance costs for a small company with up to 300 ingredients are estimated at $€ 1550$ per year.

\subsubsection{Training Costs}

As part of the experiment, we also measured the time spent on the training of new users. We found that basic training lasted for two hours. Before regular usage, it is necessary to consider two more hours per user for the repetition of the acquired knowledge and two hours on the trainer's side for the preparation of online training materials. Further training for the formulations input lasted one hour. It is necessary to add another hour on the user's side as well as on the trainer's side.

Therefore, the time spent on the training was six hours on the trainer's side as well as on the individual user's side. According to the hourly rates, the training costs were:

- For the trainer,

$$
6 \mathrm{~h} \times 70 € / \mathrm{h}=420 € \text { (the cost is included in the license price) }
$$

- For five users (the average hourly rate according to education was taken into account),

$$
5 \text { users } \times 6 \mathrm{~h} \times 24.21 € / \mathrm{h}=726 €
$$

The accumulated training costs for a small company with up to five formulators were estimated at $€ 730$.

\subsubsection{Change Management Costs}

In the present case, change management costs were assumed based on $15 \%$ of all digital transformation costs and were estimated at $€ 860$.

\subsection{The Eligibility of the Digital Process Transformation}

A comparison of the cost analysis of product development processes according to the conventional manner (Table 1) and after the digital transformation (Table 2) shows significant savings. A detailed comparison of the costs generated by individual process activities also indicates a more favorable distribution of costs (Figure 1) according to the successful completion of the new product development or unnecessary costs due to testing an unsuitable product. 


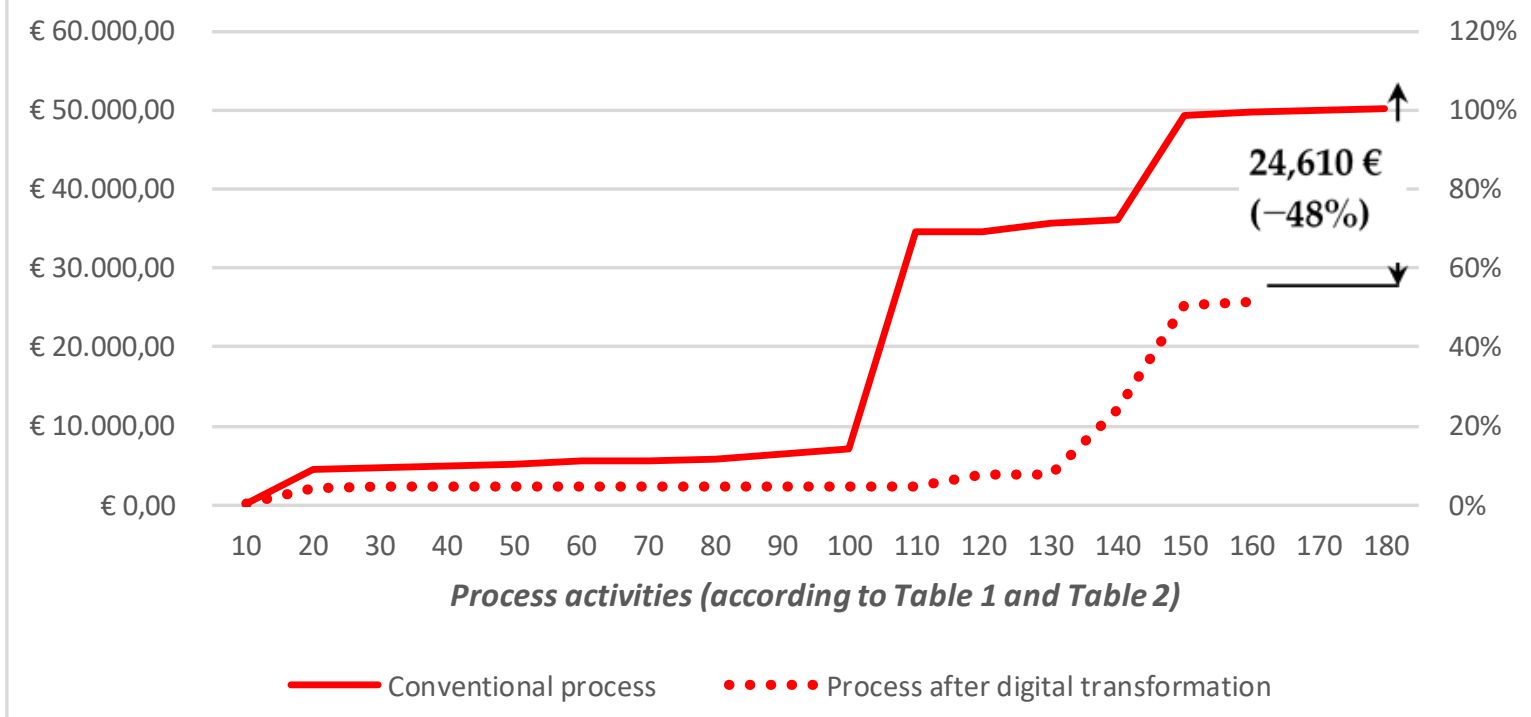

Figure 1. Costs comparison of the conventional process and the process after digital transformation.

For a selected example of a company, which successfully developed three new products per year, the structure of digital process transformation costs and potential savings are shown in the table below (Table 3).

Table 3. The cost structure of the digital process transformation and potential savings.

\begin{tabular}{cccccc}
\hline The Cost Structure & At the Beginning & After 1 Month & After 2 Month & After 3 Month & After 4 Month \\
\hline Licensing costs $(€)$ & 0.00 & 514.00 & 1028.00 & 1542.00 & 2056.00 \\
Implementation costs $(€)$ & 4343.51 & 4343.51 & 4343.51 & 4343.51 & 4343.51 \\
Maintenance costs $(€)$ & 0.00 & 129.24 & 258.47 & 387.71 & 516.95 \\
Training costs $(€)$ & 726.40 & 726.40 & 726.40 & 726.40 & 726.40 \\
Change management costs $(€)$ & 856.74 & 856.74 & 856.74 & 856.74 & 856.74 \\
\hline Total costs $(€)$ & 5926.65 & 6569.88 & 7213.12 & 7856.36 & 8499.59 \\
Process's savings $(€)$ & 0.00 & 6584.35 & $13,168.70$ & $19,753.05$ & $26,337.41$ \\
\hline
\end{tabular}

Based on these results, the investment in the digital transformation of the new product development process for the selected company was repaid after two months of successful work.

\section{Discussion and Conclusions}

In the present research, we wanted to confirm that reducing the number of laboratory tests, based on the implementation of information and communication technology (ICT), affects reducing costs in the paints and coatings development process. For this purpose, we collected data on the costs of executing individual activities in the development process.

During the data collection, the costs of materials (consumed in the development process) turned out to be practically negligible, as most suppliers of ingredients offer samples free. Free samples of ingredients for new product development are one of the manners for suppliers to gain new customers [30]. Material costs were, therefore, not included in the calculation of the eligibility of the digital process transformation.

We executed a static and dynamic labor costs simulation of executing the new product development conventional process and the process after digital transformation. A comparison of the results showed that digital transformation's most considerable savings achieved in the costs of repetitive activities (laboratory testing). The cost of this has decreased significantly due to the smaller number of repetitions, which is a consequence of the changed sequence of activities enabled by the implementation of the ICT solution [21-23] (technical enabler, which is in the present case Allchemist). The costs of other 
activities also decreased slightly due to faster and easier access to data, except for activities whose execution is related to the services of external institutions.

From the costs of developing a new product, we could confirm the justification of the digital transformation of the new paints and coatings development process. Still, it is also necessary to take into account the costs of process redesign and the implementation of an ICT solution that enables digital transformation. These costs vary significantly from company to company, so in the article, we have shown the costs of digital transformation in a selected example of a company. For the broader use of the research results, we designed a calculator to calculate the costs of process redesign and the implementation of ICT solutions. The calculator also calculates the rentability threshold (expressed in months) of use of the implemented ICT and the number of successfully developed new products. The calculator consists of an input window (Table 4) and display of the results in the table (Table 5) and graphical (Figure 2).

For any company, we could calculate the rentability threshold of the digital transformation using the calculator to help management at the decision making process.

The conducted research (analysis of process costs and costs of ICT solution implementation), as well as the designed calculator, confirmed that digital transformation of the process (redesign and implementation of appropriate ICT solution) could significantly reduce the cost of the new paints and coatings development process. We assumed that the implementation of an ICT solution with the use of a cloud-based database, which would be used together with ingredients suppliers, in addition to reducing the costs of the new paints and coatings development process, has an indirect impact on greater efficiency of ingredient procurement. A single database can have a positive impact on shortening the purchase time of ingredients, lower purchase prices of ingredients, and lower costs of ingredients handling. The correctness of the assumption will be deeply studied in further research.

Table 4. Layout of the calculator window of basic data input.

\begin{tabular}{lc}
\multicolumn{1}{c}{ Input Parameters for Calculator } & Value \\
\hline The number of annually developed products $(\#):$ & 3 \\
The average labor cost of employees in the process $(€ / \mathrm{h}):$ & 24.21 \\
The selected type of license: & Pro \\
The number of additional licenses $(\#):$ & 0 \\
The number of prepared safety data sheets $(\#):$ & $251-500$ \\
The number of hazardous ingredients used $(\#):$ & 200 \\
The decision for data transfer: & No \\
The number of ingredients in the database $(\#):$ & 300 \\
The number of formulations in the database $(\#):$ & 100 \\
The number of ingredients input by the expert $(\#):$ & 0 \\
The number of formulations input by the expert $(\#):$ & 0 \\
Labor cost-expert (€/h): & 70.00 \\
The number of training preparation's hours $(\mathrm{h}):$ & 3 \\
The number of training hours (h): & 3 \\
The number of knowledge repetition's hours $(\mathrm{h}):$ & 3 \\
Percentage of digital transformation total costs $(\%):$ & 15 \\
\hline
\end{tabular}

Table 5. Example of the rentability threshold's results in a calculator table.

\begin{tabular}{cccccc}
\hline The Cost Structure & At the Beginning & After 1 Month & After 2 Month & After 3 Month & After 4 Month \\
\hline Process's savings $(€)$ & 0.00 & 6584.35 & $13,168.70$ & $19,753.05$ \\
Licensing costs $(€)$ & 0.00 & 514.00 & 1028.00 & 1542.00 & $26,337.41$ \\
Implementation costs $(€)$ & 4343.51 & 4343.51 & 4343.51 & 4343.51 & 2056.00 \\
Maintenance costs $(€)$ & 0.00 & 129.24 & 258.47 & 387.71 & 726.40 \\
Training costs $(€)$ & 726.40 & 726.40 & 726.40 & 856.74 \\
Change management costs $(€)$ & 856.74 & 856.74 & 856.74 & 726.40 \\
Total costs $(€)$ & 5926.65 & 6569.88 & 7213.12 & 7856.36 \\
\hline
\end{tabular}




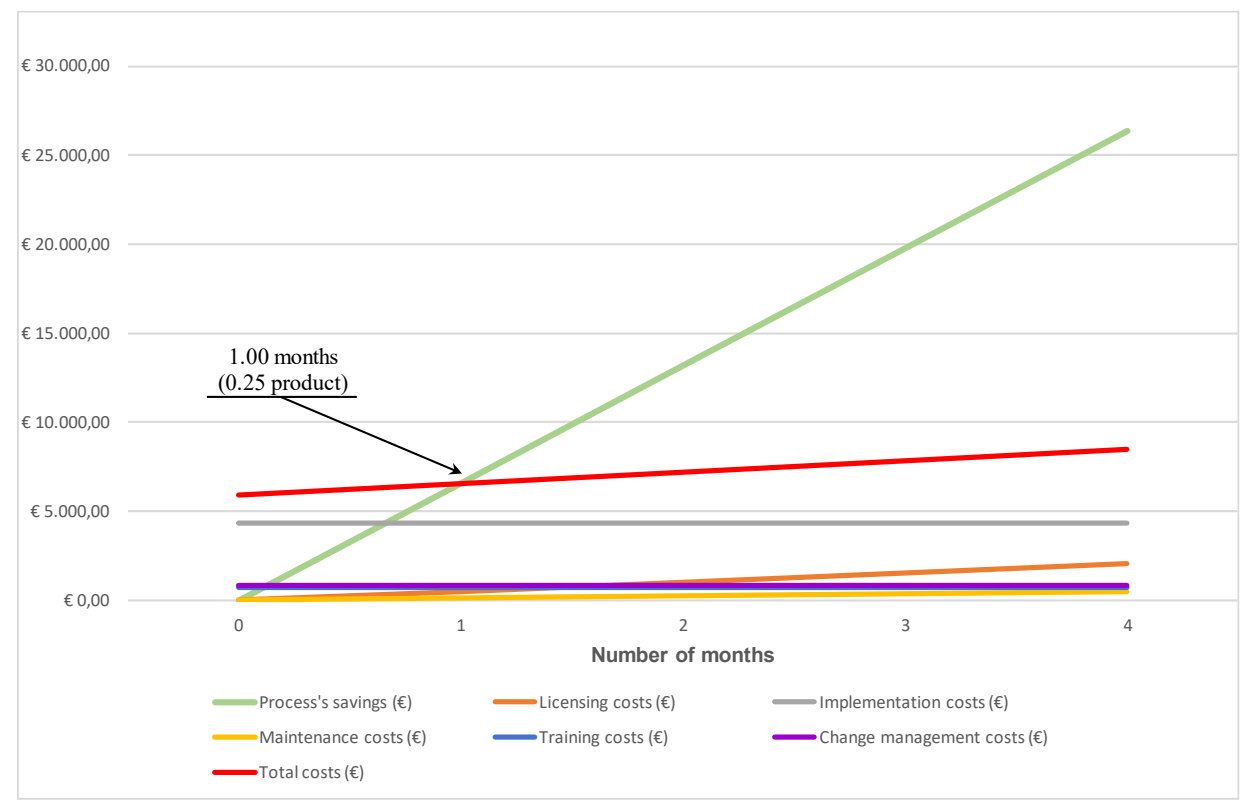

Figure 2. Example of the rentability threshold's results in a calculator.

Author Contributions: Conceptualization, T.K., and B.U.; methodology, T.K., E.K.A., and B.U.; software, T.K., E.K.A., B.U. and M.S.; validation, T.K., E.K.A., and B.U.; formal analysis, B.U.; investigation, T.K., E.K.A., B.U., and M.S.; resources, T.K.; data curation, T.K., and B.U.; writing-original draft preparation, T.K., E.K.A., B.U., and M.S.; writing—review and editing, T.K., E.K.A., B.U., and M.S.; visualization, B.U.; supervision, T.K.; project administration, T.K. All authors read and approved the final manuscript.

Funding: This research received no external funding.

Acknowledgments: The authors are grateful to the Laboratory of Enterprise Engineering, Faculty of Organizational Sciences, University of Maribor, for supporting the project.

Conflicts of Interest: The authors declare no conflict of interest.

\section{References and Note}

1. Nurioglu, A.G.; Esteves, A.C.C.; De With, G. Non-toxic, non-biocide-release antifouling coatings based on molecular structure design for marine applications. J. Mater. Chem. B. 2015, 3, 6547-6570. [CrossRef] [PubMed]

2. Akafuah, N.K.; Poozesh, S.; Salaimeh, A.; Patrick, G.; Lawler, K.; Saito, K. Evolution of the automotive body coating process-A review. Coatings 2016, 6, 24. [CrossRef]

3. Kern, T.; Krhač, E.; Senegačnik, M.; Urh, B. Digitalizing the Paints and Coatings Development Process. Processes 2019, 7, 539. [CrossRef]

4. Urh, B.; Senegačnik, M.; Kern, T.; Krhač, E. Reducing waste of laboratory tests in the coating development process. Pol. J. Environ. Stud. 2020, 29, 3841-3851. [CrossRef]

5. Eurostat. Industry by Employment Size Class (NACE Rev 2, B-E) Manufacture of Paints, Varnishes and Similar Coatings, Printing Ink and Mastics. 2019. Available online: https://appsso.eurostat.ec.europa.eu/nui/ submitViewTableAction.do (accessed on 7 November 2019).

6. Partidário, P.J.; Verdragt, P.H.J. Shaping sustainable technology development in the coatings chain Defining boundaries, environmental problems and main players. J. Clean. Prod. 2000, 8, 201-214. [CrossRef]

7. Staring, E.; Dias, A.A.; Van Benthem, R.A. New challenges for R\&D in coating resins. Prog. Org. Coat. 2002, 45, 101-117. [CrossRef]

8. Cole, I.S.; Hughes, A.E. Designing molecular protection: New paradigm for developing corrosion resistant materials uniting high throughput studies, multiscale modelling and self-repair. Corros. Eng. Sci. Technol. 2014, 49, 109-115. [CrossRef]

9. Bohorquez, S.J.; Van den Berg, P.; Akkerman, J.; Mestach, D.; Van Loon, S.; Repp, J. High-throughput paint optimisation by use of a pigment-dispersing polymer. Surf. Coat. Int. 2015, 98, 85-89. 
10. Björklund, S.; Goel, S.; Joshi, S. Function-dependent coating architectures by hybrid powder suspension plasma spaying: Injector design, processing and concept validation. Mater. Des. 2018, 142, 56-65. [CrossRef]

11. Coatingstech, Coatings Xperience: Accelerating Coatings Development with High Throughput Technology. Available online: https://www.paint.org/coatingstech-magazine/articles/accelerating-coatings-developmenthigh-throughput-technology/ (accessed on 8 May 2020).

12. Nameer, S.; Johansson, M. Fully bio-based aliphatic thermoset polyesters via self-catalyzed self-condensation of multifunctional epoxy monomers directly extracted from natural sources. J. Coat. Technol. Res. 2017, 14, 757-765. [CrossRef]

13. Ben-Arieh, D.; Qian, L. Activity-based cost management for design and development stage. Int. J. Prod. Econ. 2003, 83, 169-183. [CrossRef]

14. Nibusiness.Info.Co.UK [nd] Change Management-Cost of Change Management. Available online: https: //www.nibusinessinfo.co.uk/content/cost-change-management (accessed on 19 June 2020).

15. Moadad, S. The Hidden Costs of ERP Implementation. Medium. Available online: https://medium.com/ @shadi.moadad/the-hidden-costs-of-erp-implementation-d4eb17b7d8a6 (accessed on 21 April 2020).

16. Miller, H. 9 hidden ERP Costs that can Blow Your Implementation Budget. ERP FOCUS. Available online: https://www.erpfocus.com/hidden-erp-costs-1621.html (accessed on 16 July 2020).

17. Barreau, D. The hidden costs of implementing and maintaining information systems. Bottom Line 2001, 14, 207-212. [CrossRef]

18. Alter, S. Information Systems: A Management Perspective, 3rd ed.; Benjamin Cummings: Menlo Park, CA, USA, 1999.

19. Balantič, Z.; Polajnar, A.; Jevšnik, S. Ergonomics in Theory and Practice; National Institute for Public Health: Ljubljana, Slovenia, 2016.

20. Irani, Z.; Ghoneim, A.; Love, P.E.D. Evaluating cost taxonomies for information systems management. EJOR 2006, 73, 1103-1122. [CrossRef]

21. DKE Deutsche Kommission Elektrotechnik Elektronik Informationstechnik in DIN und VDE, German Standardization Roadmap, Industrie 4.0. Available online: https://www.din.de/blob/65354/ 57218767bd6da1927b181b9f2a0d5b39/roadmap-i4-0-e-data.pdf (accessed on 9 May 2020).

22. Gartner ®. The 2019 CIO Agenda: Securing a New Foundation for Digital Business. Available online: https://www.gartner.com/doc/3891665/cio-agenda-securing-new-foundation (accessed on 9 May 2020).

23. Challener, C. The Paint and Coatings Industry in the Age of Digitalization. Available online: https: //www.paint.org/coatingstech-magazine/articles/paint-coatings-industry-age-digitalization/ (accessed on 16 July 2020).

24. ALLCHEMIST®. Digital Platform for Experts Working in the Paint Coatings Industry Who Want to Work Directly with Data Instead of Datasheets 2018. Available online: https://www.allchemist.net/ (accessed on 7 November 2019).

25. Chamber of Commerce and Industry of Slovenia (Gospodarska Zbornica Slovenije): Plačni Kažipot—Podatki za Obračun Prejemkov (in Slovene). Available online: https://www.gzs.si/Portals/SN-Pravni-Portal/Vsebine/ novice-priponke/PK_2019_1.pdf (accessed on 21 April 2020).

26. Labour Costs, Slovenia. Republic of Slovenia Statistical Office, 2018. Available online: https://www.stat.si/ StatWeb/News/Index/8443 (accessed on 21 April 2020).

27. Pellinen, J. Costs Factors of Training-How to Calculate Your Training Budget (9.4. 2019). Available online: https://www.vuolearning.com/en/blog/training-budget (accessed on 21 April 2020).

28. Saunders, P.; Ganly, D.; Torii, D. How to Develop Initial Cost Estimates for ERP Initiatives. Gartner ${ }^{\circledR}$. Available online: https://www.gartner.com/document/3947229?ref=solrAll\&refval=253149678 (accessed on 16 June 2020).

29. ALLCHEMIST ${ }^{\circledR}$. Pricing. Internal Document of the COMPANY-Allchemist Provider

30. Spak, N.; Kuzmin, O.; Dvulit, Z.; Onysenko, T.; Sroka, W. Digitalization of the Marketing Activities of Enterprises: Case Study. Information 2020, 11, 109. [CrossRef]

(C) 2020 by the authors. Licensee MDPI, Basel, Switzerland. This article is an open access article distributed under the terms and conditions of the Creative Commons Attribution (CC BY) license (http://creativecommons.org/licenses/by/4.0/). 